\title{
Action recognition using Natural Action Structures
}

Xiaoyuan Zhu ${ }^{1,2^{*}}$, Zhiyong Yang ${ }^{1,3}$, Joe Z Tsien ${ }^{1,2}$

From Twenty First Annual Computational Neuroscience Meeting: CNS*2012

Decatur, GA, USA. 21-26 July 2012

Humans can detect, recognize, and classify natural actions in a very short time. How this is achieved by the visual system and how to make machines understand human actions have been the focus of neuro-scientific studies and computational modeling in the last several decades. A key issue is what spatial-temporal features should be encoded and what the characteristics of their occurrences are in natural actions. We propose a novel model in which Natural Action Structures (NASs) (see Figure 1), i.e., multi-size, multi-scale, spatial-temporal

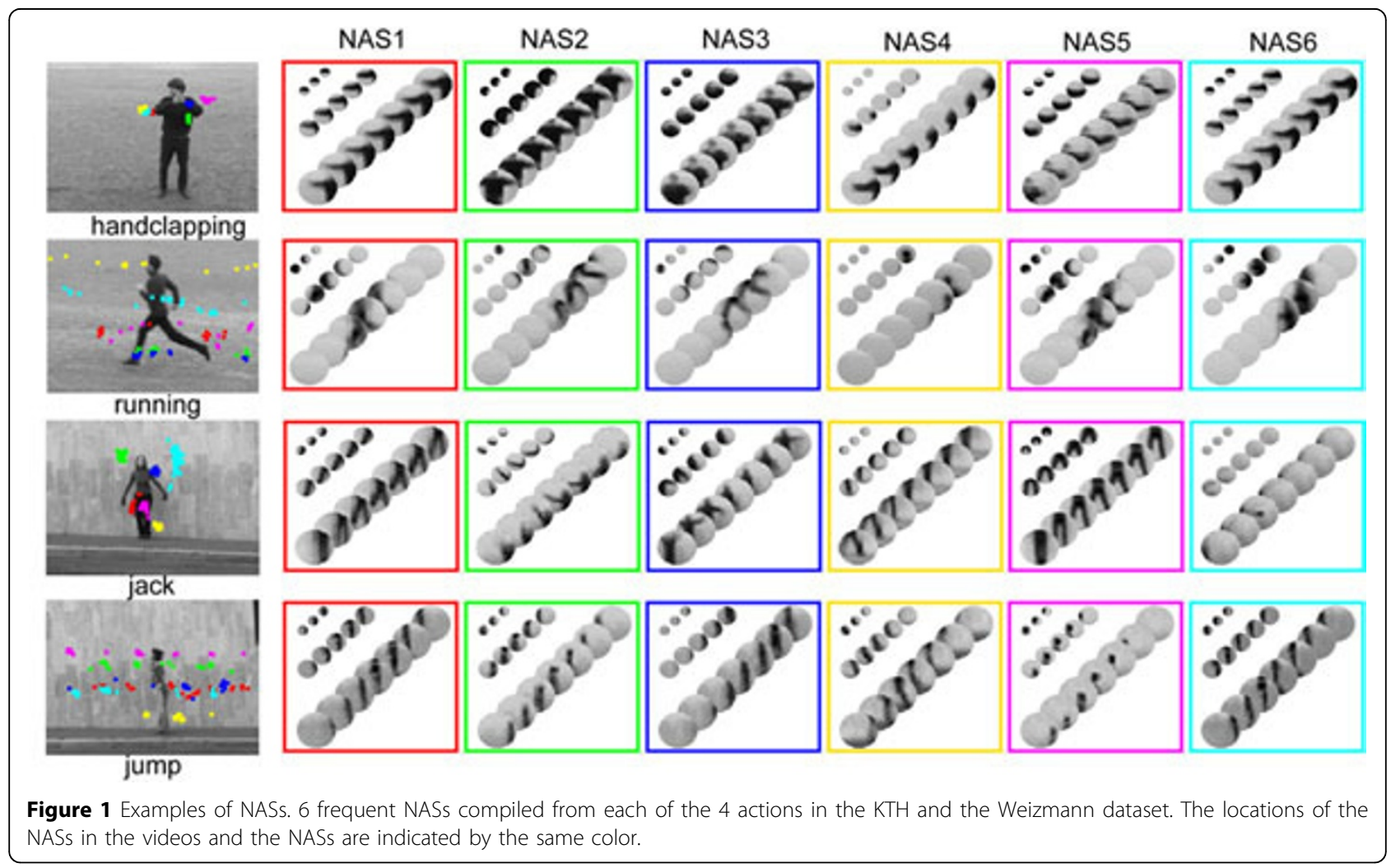

\footnotetext{
* Correspondence: xiazhu@georgiahealth.edu

${ }^{1}$ Brain and Behavior Discovery Institute, Georgia Health Sciences University,

Augusta, Georgia, 30912, USA

Full list of author information is available at the end of the article
} 
Table 1

\begin{tabular}{lll}
\hline Methods & KTH & Weizmann \\
\hline NASs & $92.7 \%$ & $96.7 \%$ \\
Cuboids & $88.5 \%$ & $94.4 \%$ \\
Yao et al. [2] & $92.0 \%$ & $95.6 \%$ \\
Niebles et al. [3] & $83.3 \%$ & $90.0 \%$ \\
\hline
\end{tabular}

concatenations of local features, serve as the basic encoding units of natural actions. In this concept, any action is a spatial-temporal concatenation of a set of NASs, which convey a full range of information about natural actions. We took several steps to extract and identify these structures and selected a set of informative natural action structures to classify a range of human actions. We found that the NASs obtained in this way achieved a significantly better recognition performance than low-level features [1] and that the performance was better than or comparable to the best current models (see Table 1).

\section{Conclusions}

NASs contain a variety of information about human actions and are robust against variations due to noises, occlusions, changes in scales, and a range of structural changes since they are concatenations of features at multiple spatial-temporal scales. The results suggest that NASs can be used as the basic encoding units of human actions and activities and may hold the key to the understanding of human ability of action recognition.

\section{Author details}

${ }^{1}$ Brain and Behavior Discovery Institute, Georgia Health Sciences University, Augusta, Georgia, 30912, USA. ²Department of Neurology, Georgia Health Sciences University, Augusta, Georgia, 30912, USA. ${ }^{3}$ Department of

Ophthalmology, Georgia Health Sciences University, Augusta, Georgia, 30912, USA.

Published: 16 July 2012

\section{References}

1. Dollár P, Rabaud V, Cottrell G, Belongie S: Behavior recognition via sparse spatio-temporal features. IEEE International Workshop on Performance Evaluation of Tracking and Surveillance (PETS) 2005, 65-72.

2. Yao A, Gall J, Van Gool LJ: A Hough transform-based voting framework for action recognition. IEEE Conference on Computer Vision and Pattern Recognition 2010, 2061-2068.

3. Niebles JC, Wang HC, Li FF: Unsupervised learning of human action categories using spatial-temporal words. International Journal of Computer Vision 2008, 79:299-318.

doi:10.1186/1471-2202-13-S1-P18

Cite this article as: Zhu et al:: Action recognition using Natural Action Structures. BMC Neuroscience 2012 13(Suppl 1):P18.

\section{Submit your next manuscript to BioMed Central} and take full advantage of:

- Convenient online submission

- Thorough peer review

- No space constraints or color figure charges

- Immediate publication on acceptance

- Inclusion in PubMed, CAS, Scopus and Google Scholar

- Research which is freely available for redistribution

Submit your manuscript at www.biomedcentral.com/submit
C Biomed Central 